\title{
The exposure of young children to accident risk as pedestrians
}

\author{
DA Routledge, R Repetto-Wright, CI Howarth
}

This paper is the seventh in a series of Injury Classic. Our goal is to reprint one such paper in each issue to initiate newcomers to the field to these old, often quoted, and important contributions. As many are difficult to find, it should help all of us to have a copy at hand. Your suggestion about future articles are welcome. Write to the editor with details of your favourite, most quoted paper.
Psychology

Department,

University of

Nottingham,

Nottingham, England

This paper first appeared in Ergonomics (1974; 17: 457-80) and is reproduced by permission of Taylor $\&$ Francis.
Pedestrian road accidents show a marked peak for children aged 5, 6 and 7 years with boys twice as involved as girls at these ages. Howarth et al (1974) described a framework in which measures of exposure were defined and related to the accident statistics to obtain estimates of absolute levels of risk for different categories of pedestrian in different traffic situations. The present paper describes a survey of children's exposure carried out to provide suitable data for this quantitative analysis. We interviewed a representative sample of Nottingham schoolchildren about their journeys in the previous 24 hours and recorded the number of roads crossed and the traffic densities of these roads. The measures of exposure obtained are presented in relation to the accompaniment of children on their journeys, the type of area in which they live, and time of day. Risk was assessed by relating exposure measures both to the national and local accident statistics. The analysis provides estimates of the risk to children of different ages and sex in their normal pattern of road crossing and in crossing roads of different traffic density and indicates that the accident statistics alone considerably underestimate the degree of risk to children under the age of eight. Interviews with a sample of the parents of the children suggest that children may provide a more accurate measure of their exposure than do their parents.

\section{Introduction}

It is tempting to attribute many of the features of the accident statistics shown in figures $1-3$, to the differing exposure of different classes of children to traffic. There is evidence in the Newsons' survey (Newson and Newson, in press) that 7 year old girls are more protected than boys of the same age, and this would provide a convenient explanation for the greater number of accidents to boys. Similarly the changes shown in figures 2 and 3 might be partially explained in terms of the greater mobility of older children. We would not expect the greater reduction in accidents between the ages of 5-15 to be explained in terms of exposure since the older children are likely to be more exposed than the young ones, and if that is the case we must conclude that the

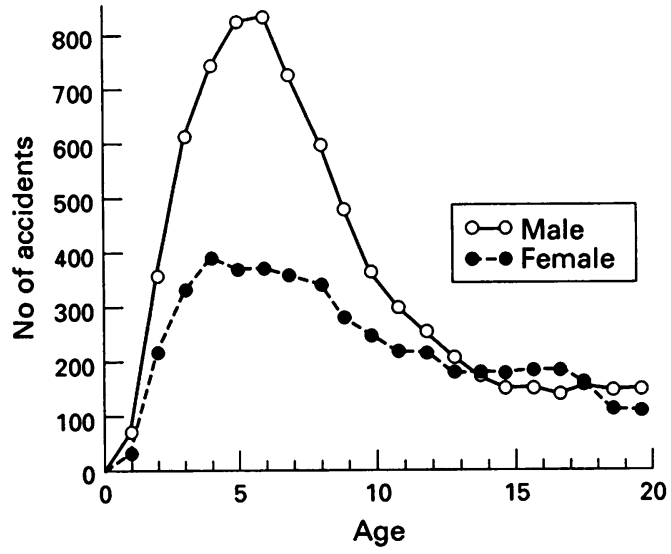

Figure 1 Average number of accidents per year (fatal and serious only) in $30 \mathrm{mph}$ speed limit areas to pedestrians aged 0-20 over the years 1966, 1967, and 1968.

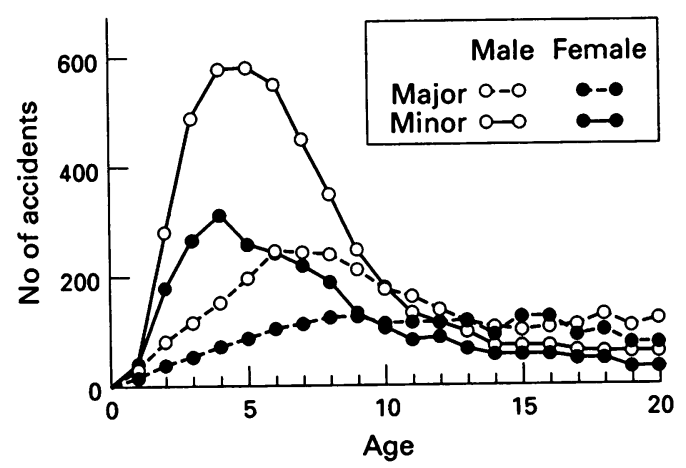

Figure 2 Average number of accidents per year (fatal and serious only) and minor roads based over the years 1966, 1967, and 1968.

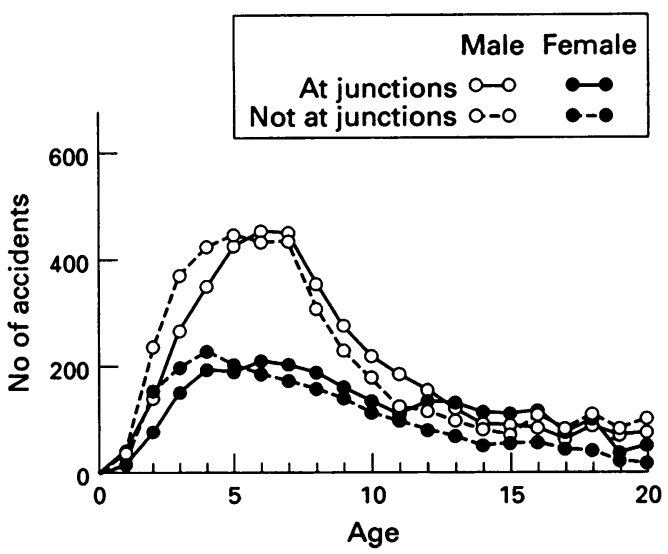

Figure 3 Average number of accidents per year (fatal and serious only) at junctions and not at junctions over the years 1966, 1967, 1968. 
accident statistics give an underestimate of the relative risk of allowing young children to cross roads.

But as Jacobs (1961) said in reference to the problem of exposure to risk situations in the causal analysis of accidents: 'Failure to recognise and deal with this problem has resulted in an unfortunate research situation. Analytical results which possess no more than speculative value are being constantly generated', and that, 'one must continue to expect that causal analytical studies of accident data without provision for exposure sampling will continue to be a futile exercise'.

The major aim of our investigations has been to seek causal explanations for the large number of accidents to child pedestrians so that preventive measures may be more soundly based. A secondary aim has been to provide behavioural measures which are clearly related to accident risk and which can be used as criteria in assessing the effectiveness of preventive measures. At present preventive measures can only be assessed by reference to the number of accidents prior to and subsequent to the introduction of new measures in a very large area and over a fairly long period. In order to achieve our two aims, observed differences in the behaviour of different age and sex groups must be related to the differences in the accident risk to children in these groups. We did not find the existing information on the exposure of children suitable for the quantitative analysis we wished to carry out, and this paper describes a study of children's exposure we have conducted ourselves and the relationship between exposure and accidents.

The Newsons' survey, a small part of which was concerned with what they called 'Avoidance of Adult Supervision', was not particularly concerned with accidents; studies by Mellinger and Manheimer (1967) are, but their measures of exposure, taken, as were the Newsons', from interviews with the mothers, are of factors which might be thought to predispose children to exposure, such as extroversion, daring and activity level, rather than exposure directly. This is not intended as criticism since they are concerned with accidents in general rather than road accidents specifically, but with regard to pedestrian accidents, disregarding a proportionately very small number, it is clear that exposure involves being in the roadway.

Since Jacobs made' the above comments a small number of studies relating children's exposure to accident risk as pedestrians have been reported. Hole (1966) surveyed 12 housing estates in London and elsewhere, providing information on the location of children's play and the degree to which they were supervised. In a study reported by Holme and Massie (1970), a very large number of children at 148 playgrounds in Britain were observed and interviewed. The distance children travelled to the playground, who accompanied them, and whether or not they crossed main roads to get to the playground were related. Recently the results of a survey commissioned by the Transport and Road Research Laboratory were pub- lished (Sadler 1972). The terms of reference of this study were specifically to assess parents' knowledge, attitudes, and behaviour in relation to the road safety of their children. A sample of 2017 mothers of children in the high accident age range 2-8 were intereviewed. They provided answers to such questions as, where the child usually played, whether the child was sent on errands, and how busy the mother thought the roads the child crossed.

Although this survey may be of considerable value within its terms of reference, as with the previously mentioned studies, no attempt is made to relate the measures to accidents precisely, nor is it possible to make precise and quantitative estimates from the information provided of the risk involved in road crossing for the two sexes at different ages. In very few tables in the report by Sadler are the data separated by sex, despite the difference between the accident rates for boys and girls at, for example, age 5 being more than twice as great as the difference between the accident rates for all children at ages 5 and 8 . The data show no difference between boys and girls in the numbers of preschool children whose usual play-place is 'in the street', except, surprisingly, at age 2 years. A greater number of boys than girls play in the street at age 5 years, but the proportion of girls playing in the street at age 5 years is surprisingly, somewhat less than at ages 3 and 4 years. Boys and girls have journeys to school that are almost identical, except that girls are very slightly more often accompanied by an adult, but this is not analysed by age. There are no sex differences between the proportions of children at each age who are allowed to cross the road outside their own homes alone.

Three other studies require mention in that they do relate measures of exposure directly to road accidents. Jacobs and Wilson (1967) compared pedestrian risk in crossing different sections of busy roads in four towns. It was found that the risk to pedestrians crossing the road varied with age; children and elderly people running greatest risk. Unfortunately all pedestrians under 16 years of age are classified as children and no further breakdown is presented. More importantly the observations, which were made during the morning and afternoon off-peak periods, are compared to the accident figures for all periods. The authors justify this on the grounds that the area distribution of accidents at the times of the pedestrian counts was not significantly different from the distribution for all hours of the day. However, it is very probable that the age and sex distributions of accidents vary considerably between different periods during the day so that comparisons of risk beween different age and sex groups based on observation and accident statistics from different periods are unlikely to be valid.

The second study (Levin and Bruce 1968) is a comparison of the locations of primary schools in two contrasting residential areas and represents a valuable contribution to the understanding of the consequences for road safety of different types of road network, par- 
ticularly in relation to the severity of injuries sustained. However, the authors were not able to compare very precisely the accident rates with their exposure measures as the accident rates used and the exposure measures taken relate to different time periods in the day, and no attempt is made to compare them for age and sex differences.

Finally, in a preliminary, unpublished study reported by Colbourne (1972) which was carried out by psychologists at the Transport and Road Research Laboratory, observers sampled the number and activities of children in the street in a residential area from 9.00 am to $7.00 \mathrm{pm}$ over a week period during the summer holidays. The age and sex distribution of pedestrian accidents in urban areas and number of children in the street were found to be fairly closely correlated. However, it is difficult to interpret these data. The measure of exposure in relation to the accident statistics provides an estimate of the risk involved in allowing a child of a given age and sex out of the house, and nothing else. It is not possible to state that one group of children behaves more dangerously than another, since any relationship found between being in the street and numbers of accidents could arise for several reasons. Unfortunately, since it was only a pilot study, the number of children observed was not sufficiently large to determine reliably the frequencies with which different categories of child pedestrians go into the road, and it cannot be assumed that they are directly related to the frequency with which each category is observed in the street. Yet it seems clear that since all but a very few accidents occur in the roadway, the most useful and direct measure of exposure is based on frequency of going in the roadway, whether in the course of a journey or in the course of other activities such as play.

We have therefore conducted a small survey of the exposure of children to traffic, to provide us with data to test some of the hypotheses thrown up by the accident statistics and our initial observations of children crossing roads. In particular we wished to assess the risk of crossing the road or going into the roadway at different ages and for the two sexes. In the analysis that follows the phrase 'crossing the road' should be understood to mean both crossing the road and entering the roadway, for example, to retrieve a ball.

\section{Conceptual framework}

We have taken as our measure of risk the average probability of a pedestrian of a given age and sex having an accident when crossing a road or entering the carriageway.

This can be said more briefly by an equation:

$$
p_{a r}=\frac{p_{a}}{\bar{r}}
$$

for a given class of pedestrian, where

$p_{a}$ is the probability of randomly selecting a pedestrian who will have an accident on a given day,

$\bar{r}$ is the mean number of roads crossed or entered by such a pedestrian in a day, $p_{a r}$ is the probability of such a pedestrian having an accident when crossing a road.

This equation and other related equations are derived in an earlier paper (Howarth et al, 1974) where the exact defintion of the quantities is set out more rigorously. The term $p_{a}$ is derived from available accident statistics, by dividing the number of accidents in a given period by the number of days and the number of children in the relevant category. We need only to estimate $\bar{r}$, the average number of roads crossed or entered per day, to be able to estimate $p_{a r}$, the probability of a given type of child having an accident if it crosses a road.

Since $\bar{r}$ refers to the existing pattern of road crossings, $p_{a r}$ calculated in this way will be the average risk run by children for their present pattern of road crossing. It cannot be used to predict the risk of crossing any particular road. To be able to do this we would need to take the density of traffic into account. We decided to do this by observing the density of traffic on each of the roads crossed by each child. We have used as a measure of the density of the traffic the quantity $p_{c}$ defined by the equation

$$
p_{c}=\frac{l+v t_{c}}{S}
$$

where $l$ is the average length of the cars, $S$ the average spacing, $v$ the average velocity and $t_{c}$ the time taken by the child to cross the path of the car: $l$ and $S$ are measured in feet, $t_{c}$ in seconds, and $v$ in feet per second. We have taken $l$ to be $14 \mathrm{ft}, v$ as $41 \mathrm{fps}$ on major roads and $32 \mathrm{fps}$ on minor roads, and $t_{c}$ as 1 second. The term $p_{c}$ is a measure of the proportion of the road taken up by traffic and hence of the probability that a child will be hit by a car if he crosses the road at random and if neither he nor the driver takes any evasive action. As such it is a measure of the effective exposure of the child who attempts to cross such a road and is independent of the ability of the child to avoid an accident.

If each road crossing is weighted by the quantity $p_{c}$ then the average daily exposure of a given class of children will be $\bar{r} \bar{p}_{c}$ when $\bar{p}_{c}$ is the average of all the $p_{c}$ values for all the children and all the roads. Since $\bar{r} \bar{p}_{c}$ is a measure of the average number of cars encountered by each child in the course of the day we have used the symbol $\bar{n}_{c}$ for it. The probability of a child having an accident if he encounters a car $\left(p_{a / c}\right)$ can be estimated from related quantities as follows:

$$
p_{a / c}=\frac{p_{a r}}{\bar{p}_{c}}=\frac{p_{a}}{\bar{r} \bar{p}_{c}}=\frac{p_{a}}{\bar{n}_{c}}
$$

\section{Method}

The child exposure survey was carried out over the months of November 1970 to February 1971, during which time a representative sample of Nottingham City children were inter- 
viewed in their schools. The age range of the sample was limited to children of primary school age (5-11), partly for administrative convenience, and partly because this is the most important group with respect to pedestrian accidents.

The sample was chosen to be as respresentative as possible of Nottingham City children while retaining administrative practicability. Newson and Newson (1968) have concluded that for the purposes of their survey work Nottingham City can be divided fairly equally into three distinct types of residential areas, namely central city, suburban, and estate. With the Newsons' help, six schools were chosen, two in each of these types of area and widely spread out across the city. The sample comprised 48 children from each of the six schools, making a total of 288 children. Within each of six age groups $(5,6,7,8,9,10 / 11), 48$ children (24 of each sex) were randomly selected from the school registers. Although it is now clear that a larger sample would have been desirable, only two interviewers were available, and it would have been undesirable that the interviews continue over a period longer than two or three months because of probable changes in the pattern of children's exposure with time of year.

The questionnaire was designed to obtain information that was as accurate as possible from all age groups. Pilot interviews indicated that the very youngest children could be expected only to recall their activities over the previous 24 hours so the main part of the interview concentrated on this time period.

Having gained prior experience of each school's catchment area, the interviewers questioned each child about his or her activities on the previous day, recording the information on a map and on the questionnaire. Information about weekend journeys was obtained on Mondays from a subsample of the children, but was subsequently felt to be too unreliable to use.

For the purpose of the analysis to be reported here, the most important source of data was a precise record of all the roads crossed in the previous 24 hours by each child in the sample, and the age of any person accompanying the child. On each map was also recorded the density of traffic so that $r$ and $p_{c}$ could be calculated for each child. The number of cars passing during two half hour periods, $3.45-4.15 \mathrm{pm}$ and $5.00-5.30 \mathrm{pm}$ was recorded for every road crossed by the children. This apparently enormous task was lightened since many of the roads carried only a small volume of traffic and by standing at a junction several roads could often be surveyed during the same period. A small pilot sample had indicated that traffic volume during the $5.00-5.30 \mathrm{pm}$ half hour period was approximately equivalent to the morning rush hour period when children are going to school, while the $3.45-4.15 \mathrm{pm}$ period when children are leaving school was approximately equivalent to the lunch hour period.

\section{Results}

Values of most of the quantities mentioned below and estimates of their variance are shown in tables 1,2 , and 3.

Figure 4 shows $\bar{r}$, the average number of roads crossed per day in each age group either with an adult, with an 8-14 year old, or alone (including with an under 7 year old). The adult accompaniment figures show a marked decline

Table $1 p_{a}, \bar{r}, \bar{n}_{c}, p_{a r}, p_{a / c}$ with standard errors of the mean for all roads

\begin{tabular}{|c|c|c|c|c|c|c|c|c|c|c|c|}
\hline & Age & $p_{a} \times 10^{6}$ & $\begin{array}{l}S D \\
p_{a} \times 10^{6}\end{array}$ & $\bar{r}$ & $\frac{S}{r} E_{m}$ & $\bar{n}_{c}$ & $\frac{S}{n_{c}} E_{m}$ & $p_{a r} \times 10^{6}$ & $\begin{array}{l}S E_{m} \\
p_{a r} \times 10^{6}\end{array}$ & $p_{a / c} \times 10^{6}$ & $\begin{array}{l}S E_{m} \\
p_{a / c} \times 10^{6}\end{array}$ \\
\hline Males & $\begin{array}{r}5 \\
6 \\
7 \\
8 \\
9 \\
10\end{array}$ & $\begin{array}{l}5 \cdot 78 \\
6 \cdot 07 \\
5 \cdot 80 \\
5 \cdot 27 \\
4 \cdot 13 \\
3 \cdot 27\end{array}$ & $\begin{array}{l}0.35 \\
0.35 \\
0.35 \\
0.33 \\
0.29 \\
0.26\end{array}$ & $\begin{array}{l}3 \cdot 60 \\
4 \cdot 64 \\
5 \cdot 21 \\
6 \cdot 89 \\
9 \cdot 40 \\
9 \cdot 69\end{array}$ & $\begin{array}{l}0.75 \\
0.89 \\
1.00 \\
1.13 \\
1.14 \\
1.30\end{array}$ & $\begin{array}{l}0.084 \\
0.185 \\
0.184 \\
0.343 \\
0.567 \\
0.407\end{array}$ & $\begin{array}{l}0.020 \\
0.040 \\
0.041 \\
0.091 \\
0.176 \\
0.098\end{array}$ & $\begin{array}{l}1.61 \\
1.52 \\
1.11 \\
0.77 \\
0.44 \\
0.34\end{array}$ & $\begin{array}{l}0.35 \\
0.31 \\
0.22 \\
0.14 \\
0.06 \\
0.05\end{array}$ & $\begin{array}{r}68 \cdot 80 \\
38 \cdot 22 \\
31 \cdot 52 \\
15 \cdot 36 \\
7 \cdot 28 \\
8 \cdot 03\end{array}$ & $\begin{array}{r}17 \cdot 10 \\
8 \cdot 50 \\
7 \cdot 34 \\
4 \cdot 19 \\
2 \cdot 32 \\
2 \cdot 04\end{array}$ \\
\hline Females & $\begin{array}{r}5 \\
6 \\
7 \\
8 \\
9 \\
10\end{array}$ & $\begin{array}{l}2 \cdot 54 \\
2 \cdot 67 \\
2 \cdot 75 \\
2 \cdot 59 \\
2 \cdot 30 \\
2 \cdot 22\end{array}$ & $\begin{array}{l}0.23 \\
0.23 \\
0 \cdot 24 \\
0 \cdot 23 \\
0 \cdot 22 \\
0 \cdot 21\end{array}$ & $\begin{array}{l}3 \cdot 17 \\
4 \cdot 48 \\
6 \cdot 52 \\
4 \cdot 75 \\
6 \cdot 54 \\
8 \cdot 12\end{array}$ & $\begin{array}{l}0.96 \\
0.98 \\
1.36 \\
0.75 \\
1.16 \\
1.62\end{array}$ & $\begin{array}{l}0 \cdot 102 \\
0 \cdot 115 \\
0.197 \\
0.154 \\
0.315 \\
0.290\end{array}$ & $\begin{array}{l}0.036 \\
0.046 \\
0.058 \\
0.028 \\
0.082 \\
0.064\end{array}$ & $\begin{array}{l}0.80 \\
0.58 \\
0 \cdot 42 \\
0.55 \\
0 \cdot 35 \\
0 \cdot 27\end{array}$ & $\begin{array}{l}0.25 \\
0.14 \\
0.09 \\
0 \cdot 18 \\
0.22 \\
0.06\end{array}$ & $\begin{array}{r}24.90 \\
22 \cdot 70 \\
13.96 \\
16 \cdot 81 \\
7 \cdot 30 \\
7.66\end{array}$ & $\begin{array}{l}9 \cdot 09 \\
9 \cdot 18 \\
4 \cdot 31 \\
3.43 \\
2.03 \\
1.84\end{array}$ \\
\hline
\end{tabular}

Table $2 p_{a}, \bar{r}, \bar{n}_{c}, p_{a r}, p_{a / c}$ with standard errors of the mean for major roads

\begin{tabular}{|c|c|c|c|c|c|c|c|c|c|c|c|}
\hline & Age & $p_{a} \times 10^{6}$ & $\begin{array}{l}S D \\
p_{a} \times 10^{6}\end{array}$ & $\bar{r}$ & $\frac{S}{\bar{r}} E_{m}$ & $\bar{n}_{c}$ & $\begin{array}{l}S E_{m} \\
\bar{n}_{c}\end{array}$ & $p_{a r} \times 10^{6}$ & $\underset{p_{a r} \times 10^{6}}{S E_{m}}$ & $p_{a / c} \times 10^{6}$ & $\begin{array}{l}S E_{m} \\
p_{a / c} \times 10^{6}\end{array}$ \\
\hline Males & $\begin{array}{r}5 \\
6 \\
7 \\
8 \\
9 \\
10\end{array}$ & $\begin{array}{l}1.91 \\
2.33 \\
2 \cdot 47 \\
2.49 \\
2.24 \\
1.95\end{array}$ & $\begin{array}{l}0 \cdot 20 \\
0 \cdot 22 \\
0 \cdot 23 \\
0 \cdot 23 \\
1 \cdot 21 \\
0 \cdot 20\end{array}$ & $\begin{array}{l}0.063 \\
0.104 \\
0.229 \\
0.354 \\
0.979 \\
0 \cdot 167\end{array}$ & $\begin{array}{l}0 \cdot 30 \\
0 \cdot 35 \\
0 \cdot 09 \\
0 \cdot 18 \\
0 \cdot 48 \\
0 \cdot 10\end{array}$ & $\begin{array}{l}0.016 \\
0.014 \\
0.030 \\
0.124 \\
0.326 \\
0.034\end{array}$ & $\begin{array}{l}0.016 \\
0.008 \\
0.013 \\
0.070 \\
0.166 \\
0.025\end{array}$ & $\begin{array}{r}30 \cdot 32 \\
22 \cdot 40 \\
10 \cdot 79 \\
7.03 \\
2 \cdot 29 \\
11.68\end{array}$ & $\begin{array}{r}143.80 \\
74.93 \\
4.36 \\
3.62 \\
1.14 \\
7.09\end{array}$ & $\begin{array}{r}120 \cdot 13 \\
165 \cdot 25 \\
83.74 \\
20 \cdot 10 \\
6 \cdot 86 \\
56.69\end{array}$ & $\begin{array}{r}99.08 \\
91.91 \\
40.08 \\
11.52 \\
3.56 \\
40.51\end{array}$ \\
\hline Females & $\begin{array}{r}5 \\
6 \\
7 \\
8 \\
9 \\
10\end{array}$ & $\begin{array}{l}0.91 \\
1.07 \\
1.17 \\
1.38 \\
1.23 \\
1.34\end{array}$ & $\begin{array}{l}0 \cdot 14 \\
0 \cdot 15 \\
0 \cdot 16 \\
0 \cdot 17 \\
0 \cdot 16 \\
0 \cdot 17\end{array}$ & $\begin{array}{l}0 \cdot 125 \\
0.042 \\
0 \cdot 146 \\
0 \cdot 146 \\
0.458 \\
0.333\end{array}$ & $\begin{array}{l}0.07 \\
0 \cdot 20 \\
0.08 \\
0 \cdot 08 \\
0 \cdot 21 \\
0 \cdot 17\end{array}$ & $\begin{array}{l}0 \cdot 046 \\
0.012 \\
0 \cdot 026 \\
0 \cdot 031 \\
0 \cdot 127 \\
0 \cdot 109\end{array}$ & $\begin{array}{l}0.026 \\
0.012 \\
0.015 \\
0.015 \\
0.070 \\
0.053\end{array}$ & $\begin{array}{r}7 \cdot 28 \\
25 \cdot 48 \\
8.01 \\
9 \cdot 45 \\
2.69 \\
4.02\end{array}$ & $\begin{array}{r}4.37 \\
120 \cdot 16 \\
4.42 \\
5 \cdot 18 \\
1 \cdot 28 \\
2 \cdot 13\end{array}$ & $\begin{array}{r}19 \cdot 96 \\
88 \cdot 43 \\
44 \cdot 32 \\
44 \cdot 52 \\
9 \cdot 72 \\
12 \cdot 35\end{array}$ & $\begin{array}{r}11.91 \\
87.50 \\
25.26 \\
23.05 \\
5.52 \\
6.24\end{array}$ \\
\hline
\end{tabular}


Table $3 p_{a}, \bar{r}, \bar{n}_{c}, p_{a r}, p_{a / c}$ with standard errors of the mean for minor roads

\begin{tabular}{|c|c|c|c|c|c|c|c|c|c|c|c|}
\hline & Age & $p_{a} \times 10^{6}$ & $\begin{array}{l}S D \\
p_{a} \times 10^{6}\end{array}$ & $\bar{r}$ & $\frac{S}{r} E_{m}$ & $\bar{n}_{c}$ & $\frac{S}{\bar{n}_{c}} E_{m}$ & $p_{a r} \times 10^{6}$ & $\begin{array}{l}S E_{m} \\
p_{a r} \times 10^{6}\end{array}$ & $p_{a / c} \times 10^{6}$ & $\begin{array}{l}S E_{m} \\
p_{a / c} \times 10^{6}\end{array}$ \\
\hline Males & $\begin{array}{r}5 \\
6 \\
7 \\
8 \\
9 \\
10\end{array}$ & $\begin{array}{l}3.87 \\
3.74 \\
3.33 \\
2.78 \\
1.89 \\
1.32\end{array}$ & $\begin{array}{l}0 \cdot 28 \\
0 \cdot 28 \\
0 \cdot 26 \\
0 \cdot 24 \\
0 \cdot 20 \\
0 \cdot 16\end{array}$ & $\begin{array}{l}3.54 \\
4.54 \\
4.98 \\
6.54 \\
8.42 \\
9.52\end{array}$ & $\begin{array}{l}0.69 \\
0.82 \\
1.00 \\
1 \cdot 12 \\
1.03 \\
1.30\end{array}$ & $\begin{array}{l}0.068 \\
0.171 \\
0.154 \\
0.219 \\
0.241 \\
0.374\end{array}$ & $\begin{array}{l}0.013 \\
0.039 \\
0.040 \\
0.059 \\
0.059 \\
0.095\end{array}$ & $\begin{array}{l}0.86 \\
0.82 \\
0 \cdot 67 \\
0 \cdot 43 \\
0 \cdot 22 \\
0 \cdot 14\end{array}$ & $\begin{array}{l}0 \cdot 18 \\
0 \cdot 16 \\
0 \cdot 15 \\
0.08 \\
0.04 \\
0.03\end{array}$ & $\begin{array}{r}56.91 \\
21.87 \\
21.62 \\
12.69 \\
7.84 \\
3.53\end{array}$ & $\begin{array}{l}9 \cdot 24 \\
5 \cdot 24 \\
6 \cdot 01 \\
3 \cdot 60 \\
2 \cdot 07 \\
1 \cdot 00\end{array}$ \\
\hline Females & $\begin{array}{r}5 \\
6 \\
7 \\
8 \\
9 \\
10\end{array}$ & $\begin{array}{l}1.63 \\
1.54 \\
1.58 \\
1.21 \\
1.07 \\
0.88\end{array}$ & $\begin{array}{l}0 \cdot 18 \\
0 \cdot 18 \\
0 \cdot 18 \\
0 \cdot 16 \\
0 \cdot 15 \\
0 \cdot 13\end{array}$ & $\begin{array}{l}3 \cdot 04 \\
4 \cdot 44 \\
6 \cdot 37 \\
4 \cdot 60 \\
6 \cdot 08 \\
7 \cdot 79\end{array}$ & $\begin{array}{l}0.96 \\
0.96 \\
1.36 \\
0.75 \\
1.14 \\
1.49\end{array}$ & $\begin{array}{l}0.056 \\
0 \cdot 103 \\
0 \cdot 171 \\
0 \cdot 128 \\
0 \cdot 189 \\
0 \cdot 182\end{array}$ & $\begin{array}{l}0.025 \\
0.044 \\
0.056 \\
0.024 \\
0.044 \\
0.036\end{array}$ & $\begin{array}{l}0.54 \\
0 \cdot 35 \\
0 \cdot 24 \\
0 \cdot 26 \\
0 \cdot 18 \\
0 \cdot 11\end{array}$ & $\begin{array}{l}0.180 \\
0.185 \\
0.057 \\
0.055 \\
0.042 \\
0.042\end{array}$ & $\begin{array}{r}29 \cdot 11 \\
14.95 \\
9.24 \\
9.45 \\
5.66 \\
4.84\end{array}$ & $\begin{array}{r}13 \cdot 38 \\
6 \cdot 42 \\
3 \cdot 25 \\
2 \cdot 18 \\
1.52 \\
1 \cdot 18\end{array}$ \\
\hline
\end{tabular}

A. Adults

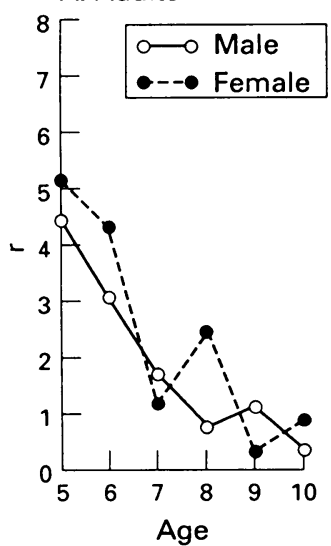

B. 8-14

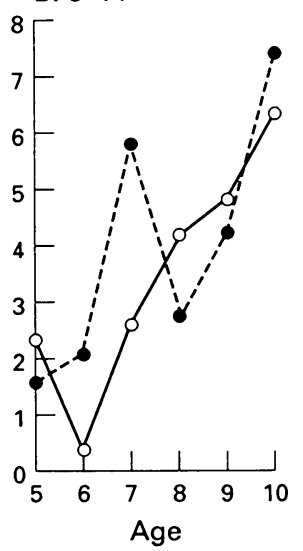

C. Alone or $+<7$

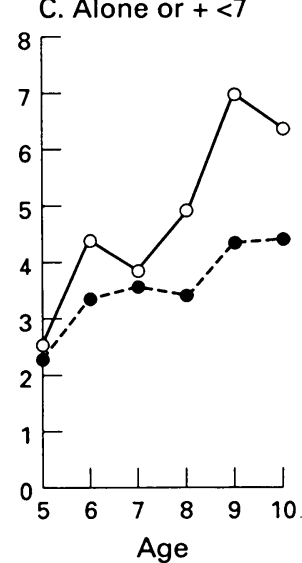

Figure 4 Mean number of roads crossed per child per day $(\bar{r})$, with adults, 8-14 year olds, alone and with under 7 year olds.

with age for both sexes, girls being accompanied by adults slightly more than boys, as would be expected from the Newsons' (personal communication 1973) and Sadler's (1972) studies. The number of roads crossed with another child or children aged between 8-14 years increases with age, and the younger girls are more often accompanied by an older child than the younger boys. However, the expected greater amount of independent travelling by boys is not very marked until the ages of 8,9 , and 10 .

It seemed highly probable that a child travelling alone would be more at risk than when he is with an adult or even another child. To get a total exposure figure we initially weighted each road crossed with an adult as zero risk, each road crossed with an older child as 0.5 (on the grounds that the older child would effectively accept the responsibility for the crossing approximately half the time), and each road crossed alone as $1 \cdot 0$. On this rather arbitrary basis we get figure 5 which shows no sex difference in exposure below the age of 8 .

Preliminary analysis of data so far collected in an on-going study of pedestrian accidents by the Transport and Road Research Laboratory indicated that $10 \%$ of children involved in accidents as pedestrians were accompanied by an adult at the time of the accident, $45 \%$ were with another child, and $45 \%$ were alone. Unfortunately, insufficient data has as yet been collected to break these figures down by age and sex. Such a breakdown when related to $\bar{r}$ and $\bar{n}_{c}$ would enable us to calculate the extent to which risk is reduced by accompaniment. In the absence of this information the best approximation possible is the ratio of the proportion of roads crossed alone, with another child and with an adult, by all the children, to the proportions of accidents to children so accompanied. The value $p_{a r}$ for all the children in the sample, alone with another child, and with an adult are found to be in the ratio $1 \cdot 0,0.64$, and 0.32 respectively. The effect of using these values to weight each road crossed is mainly to increase the value of $\bar{n}_{c}$ and $\bar{r}$ and decrease the values of $p_{a r}$ and $p_{a / c}$ for the younger age groups. The relative difference in risk between the younger and older children is somewhat lessened although still very marked. The relative difference in risk between the two sexes is unaffected. Part of the reduction in the effect of age on $p_{a / c}$ is due to the false assumption that the proportion of accidents when accompanied or alone will not be affected by age. Neither method of weighting is satisfactory, but they

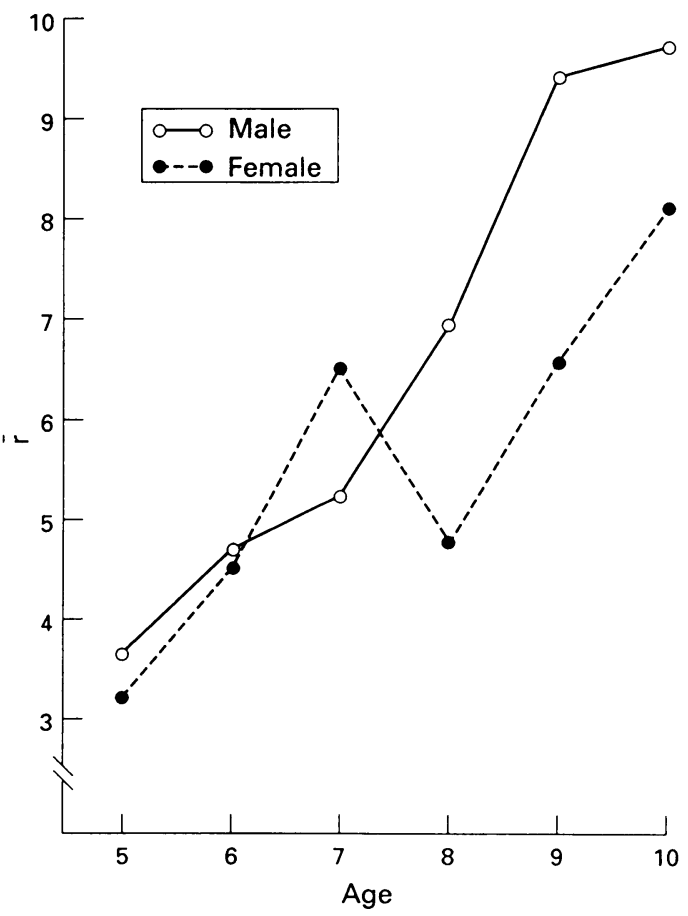

Figure 5 Mean number of roads crossed per day $(\bar{r})$ weighted by accompaniment. 
probably represent upper and lower limits to the estimates of $p_{a / c}$ which will be discussed later.

In order to estimate the risk per road crossing, we have taken the accident statistics for the winter months on weekdays only, averaged over the years 1966-1970. By dividing the probability of an accident by our estimate of the average number of roads crossed per day weighted by degree of accompaniment, we get an estimate of the risk per road crossing $\left(p_{a r}\right)$. This is shown in figure 6 by age and sex. It can be seen that after allowance has been made for exposure, the younger boys are taking approximately twice as much risk in crossing the roads as girls of the same age. The difference in risk has disappeared by the age of 8 . For both sexes the risk falls dramatically with age. Boys age 5 are 5 times as much at risk as boys age 10. For girls between the same ages, the risk falls by a factor of 3 .

The same data allow us to calculate the relative risk of crossing major roads and minor roads, since the national accident statistics can be broken down in this way, and the classification of the roads in our sample is known. Figure 7 shows the risk calculated in this way, by age and sex. The greater danger of crossing a major road is apparent, but the effect of age is similar on both types of road. The most obvious cause of the greater risk on the major roads is the greater density of traffic.

In figure 8 the value of $\bar{n}_{c}$ for each degree of accompaniment is set out for each age and sex. By comparison with figure 4 it shows a less steep reduction in accompaniment by adults, presumably because adults continue to accompany children on the more busy roads. It shows a smaller increase of accompaniment by $8-14$ year olds, particularly for boys. This is perhaps because younger children are more likely to be

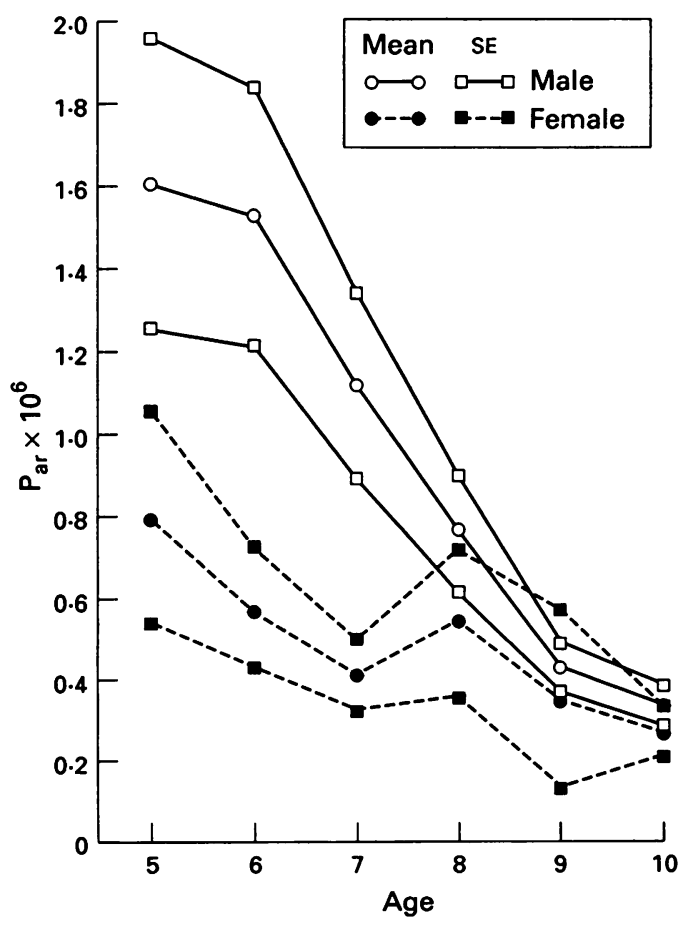

Figure 6 Risk per road crossing $\left(p_{a \mid r}\right)$ on all roads. accompanied by older children on the busy roads. It also shows a greater proportionate increase in exposure to children travelling alone or with younger children, presumably because the older children are allowed to travel on busier roads.

In figure 9 an overall value of $\bar{n}_{c}$ has been derived as before from the initial weighting for accompaniment, as in figure 5 . The picture is very similar to that of figure 5 but the change of exposure with age is rather greater.

In figure 10 is shown $p_{a / c}$ the risk per encounter with a car. Here we are assuming that $p_{a / c}$ can be calculated by dividing the probability of an accident per day $\left(p_{a}\right)$ by the average number of encounters with a car per day $\left(\bar{n}_{c}\right)$, ie

$$
p_{a / c}=\frac{p_{a}}{\bar{n}_{c}} .
$$

It is in relation to figure 10 that the effects of our arbitrary weighting for accompaniment are most strongly felt. The second weighting derived from the TRRL accident breakdown produces a slightly different set of estimates of $p_{a / c}$ as shown in table 4 . Roads crossed with an adult are now weighted by 0.32 rather than zero. Since many of these roads carry a high density of traffic $\bar{n}_{c}$ is increased relatively more than $\bar{r}$.

It can be seen that the main effect is to reduce $P_{a / c}$ for the younger children and particulaly for the boys. It is probably too great a reduction
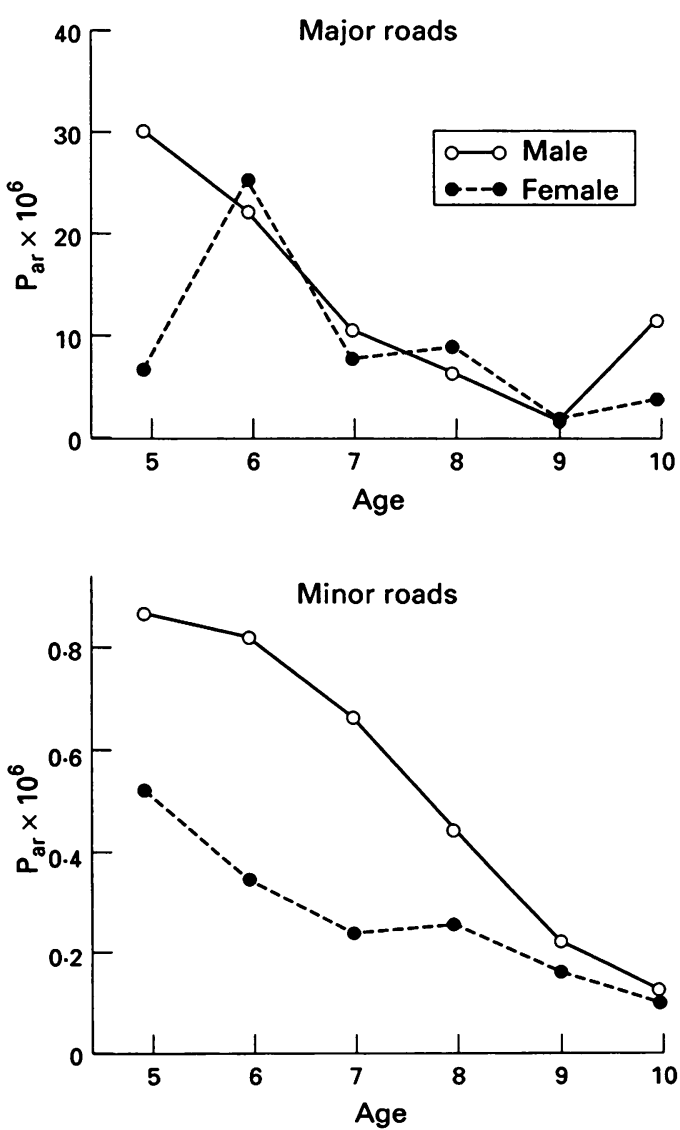

Figure 7 Risk per road crossing $\left(p_{a \mid r}\right)$ on major and minor roads. 

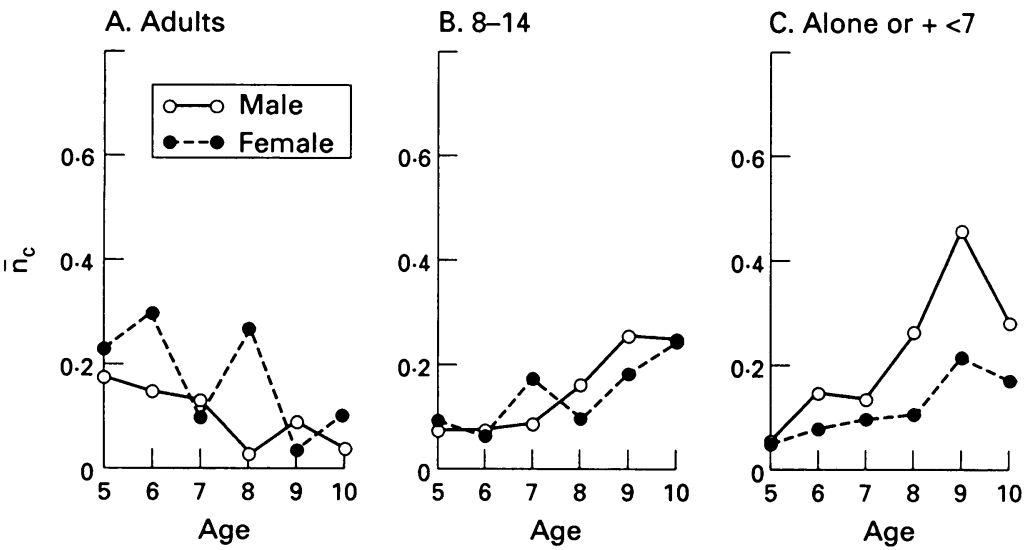

Figure 8 Average number of cars encountered per day $\left(\bar{n}_{c}\right)$ with adults, 8-14 year olds, alone and with under 7 year olds.

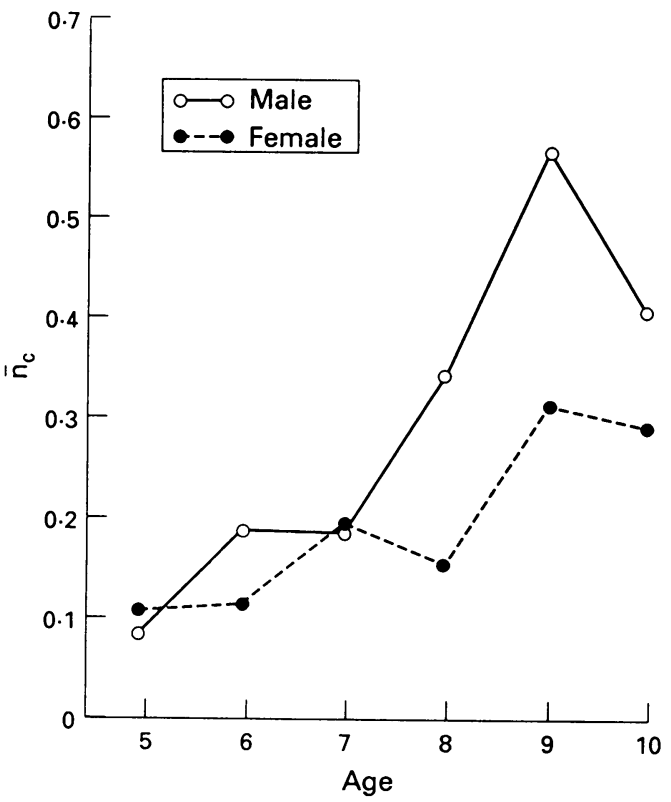

Figure $9 \bar{n}_{c}$ for all roads by age and sex.

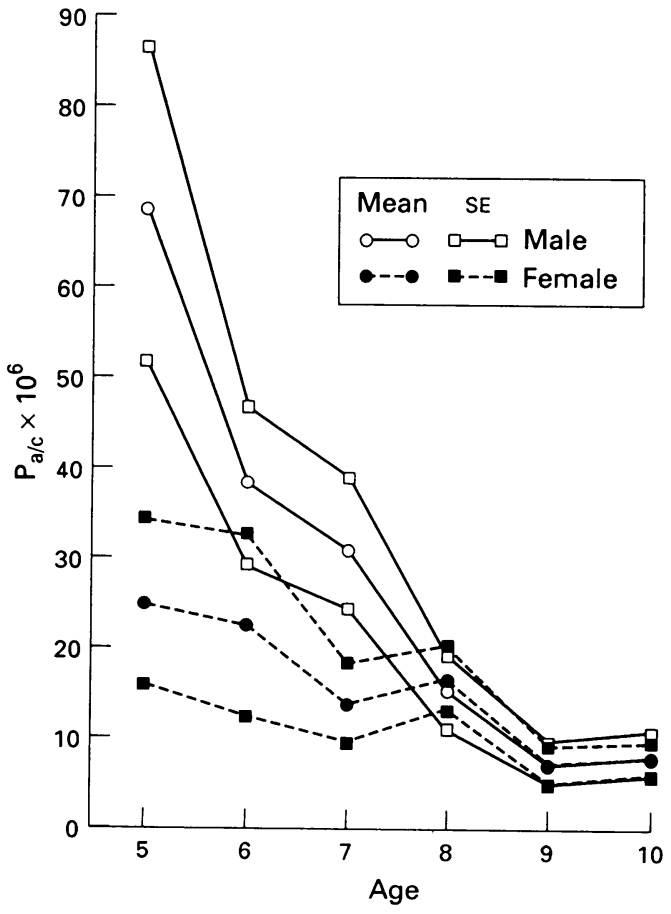

Figure 10 Risk per encounter with a car $p_{a / c}$ on all roads.
Table 4 The effect of different weightings for accompaniment on $p_{a}$

\begin{tabular}{lccc}
\hline & Age & $p_{a i c}$ first weighting & $\begin{array}{l}p_{a j c} \text { second weigh- } \\
\text { ting }\end{array}$ \\
\hline \multirow{4}{*}{ Male } & 5 & $68.80 \times 10^{-6}$ & $36.13 \times 10^{-6}$ \\
& 6 & $38.22 \times 10^{-6}$ & $22.48 \times 10^{-6}$ \\
& 7 & $31.52 \times 10^{-6}$ & $24.17 \times 10^{-6}$ \\
& 8 & $15.36 \times 10^{-6}$ & $13.87 \times 10^{-6}$ \\
& 9 & $7.28 \times 10^{-6}$ & $6.35 \times 10^{-6}$ \\
& 10 & $8.03 \times 10^{-6}$ & $7.11 \times 10^{-6}$ \\
& 5 & $24.90 \times 10^{-6}$ & $14.11 \times 10^{-6}$ \\
& 6 & $22.70 \times 10^{-6}$ & $11.61 \times 10^{-6}$ \\
& 7 & $13.96 \times 10^{-6}$ & $10.58 \times 10^{-6}$ \\
& 8 & $16.81 \times 10^{-6}$ & $9.25 \times 10^{-6}$ \\
& 9 & $7.30 \times 10^{-6}$ & $6.22 \times 10^{-6}$ \\
& 10 & $7.66 \times 10^{-6}$ & $5.84 \times 10^{-6}$ \\
\hline
\end{tabular}

and these figures are presented side by side to show the effect of different weightings for accompaniment. Further data will allow more adequate weighting, but our impression is that the final estimates will lie between the two shown here.

Just as figure 5 showed the risk normally taken by children crossing the kind of road we expect them to cross, so figure 10 estimates, among other things, the relative risk of asking children of different ages to cross the same road. It is also an estimate of the skill which children exhibit in crossing roads and its resemblance to a learning, or a maturational curve is not surprising. Indeed, it probably reflects processes of both maturation and learning.

If it turns out that $p_{a / c}$, the probability of having an accident per encounter with a car, is independent of road type, then it could be used to calculate the consequences of asking children to cross roads with different traffic densities, so that simply from observations of traffic densities, we might be able to predict accident figures and the consequences of simple preventive measures.

We can now return to the question of whether the greater risk in crossing major roads is entirely due to the increased density of traffic. This is not so trivial a question as it may at first appear. One feature of children's behaviour on main roads, that has become apparent from other studies we have conducted, is that they nearly always pay great attention to the traffic, so that if heedlessness is a major cause of accidents we might expect that the risk per encounter with a car would actually be less on the major roads. On the other hand, if skill is an important factor then the greater difficult of dealing with main road traffic, because of its higher speed and density, should lead to a higher risk per encounter, for the main roads.

Figure 11 shows the data of figure 7 weighted by exposure, as in figure 10 . It can be seen that although the risks on major and minor roads are much more alike when measured in this way, the major roads still show a higher level of risk, particularly for the boys. If this result were confirmed it would be not unreasonable to interpret it as evidence that skill, in addition to heedlessness, is an important determiner of accidents on roads with a high density of traffic. It is unfortunate that the estimate of risk on major roads for both boys and girls is very 
unreliable because of the very small exposure figures.

A great deal of extra information can be extracted from the exposure survey, although it is limited by the small sample size.

The distribution of exposure scores $\left(n_{c}\right)$ at each age is very highly skewed with a surprising number of children receiving zero scores. The distribution is also very wide, so that the average exposure may be a poor measure to use because it is so much affected by a few extremely high scores. The median would in some ways be a better measure but is not

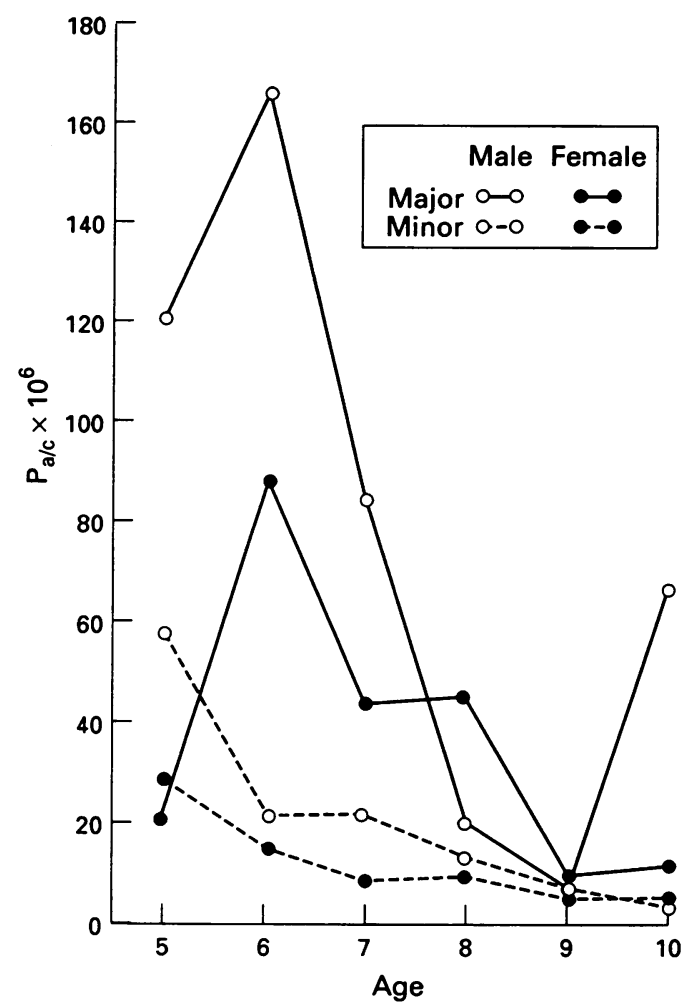

Figure 11 Risk per encounter with a car $p_{a / c}$ on major and minor roads.
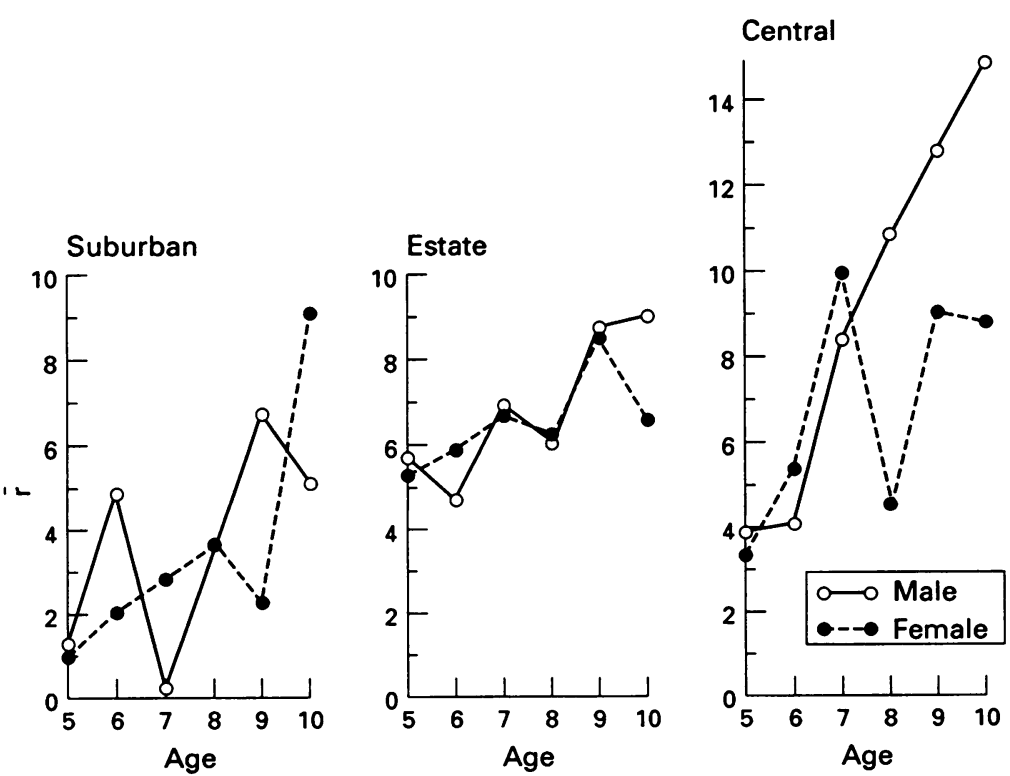

Figure 12 Mean number of roads crossed per day $(\bar{r})$ by children in suburban, estate, and central areas. appropriate to the arithmetical manipulations we have done on the data.

Figure 12 shows how the road crossing scores $(\bar{r})$ vary in the three different areas, while figure 13 shows the same score weighted for density of traffic $\left(\bar{n}_{c}\right)$. The greater density of city centre traffic is clearly very important in determining the exposure of the city centre children. It is also apparent that the greater exposure of boys to traffic is largely a city centre phenomenon. Our map of accidents in the City of Nottingham over the past three years shows a concentration of accidents in the central areas which could be partially explained in terms of the greater density of traffic and the consequently greater exposure of city centre children. One other interesting feature of these figures is the difference in the way exposure changes with age in the different areas. In the city centre the very young children are apparently protected from traffic; the exposure rises rapidly with age. On the estates exposure is comparatively high at age 5 and 6 but does not increase very rapidly. In the suburban areas exposure is comparatively low at all ages, but becomes comparable with that of the estate children at ages 9 and 10 .

Part of the explanation for the differences in the exposure of children in different areas lies in the mode of travel to and from school: $98 \%$ of the central area children walked to school and none travelled by car, whereas in the suburban areas $26 \%$ of the children travelled to school by car and only $68 \%$ walked, the remainder travelling by bus for at least part of the journey. This difference is highly significant $(p<0.001)$ on a $\chi^{2}$ test.

There is also a significant difference in the numbers of children in each area who made a journey, either to a shop or a friend or relative, before going to school in the morning: $23 \%$ of the central area children as opposed to only $4 \%$ of the suburban children claimed to have made such journeys. Newson and Newson (personal communication 1973) report a similar social class difference in the frequency with which mothers of 7 year old children say that they send their children out shopping and on other errands. They suggest that the explanation lies in the proximity of 'corner shops' in the working class localities.

There is also an area difference in the numbers of children in our sample who stayed at school for lunch on the day in question: $30 \%$, $40 \%$, and $54 \%$ in the estate, central, and suburban areas respectively. A child who goes home to lunch makes twice as many journeys in the day as a child who says at school and, as can be seen from table 5 , the values of both $\bar{r}$ and $\bar{n}_{c}$ for children making lunch time journeys are rather higher than for children staying at school. However, the values of $\bar{r}$ and $\bar{n}_{c}$ for children who go out in the evening are even higher whether or not they go home for lunch. In fact these latter values are almost certainly underestimates due to the difficulty of assessing, in an interview, children's exposure when out playing rather than travelling on a specific journey. Figure 14 shows the way exposure changes with time of day. The main finding is 

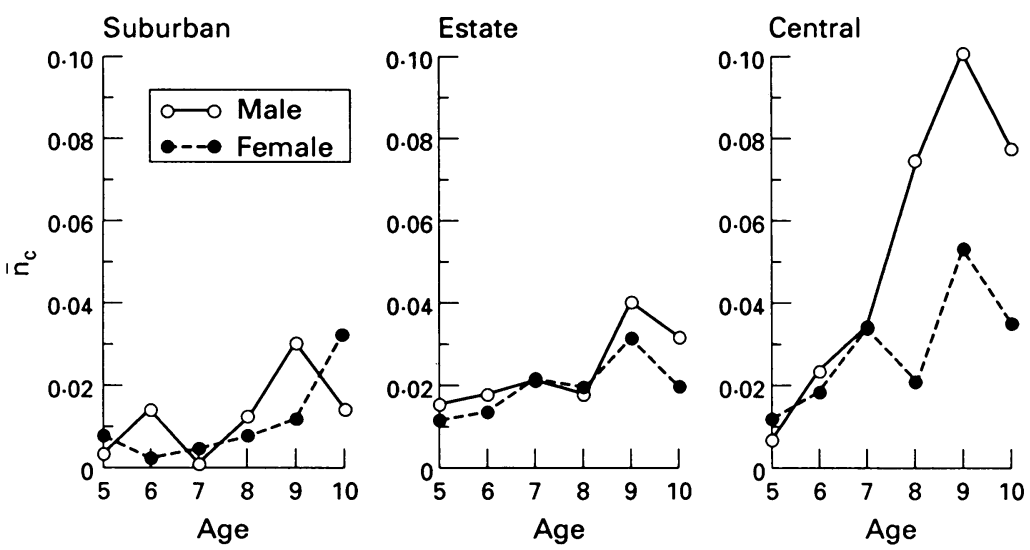

Figure 13 Average number of cars encountered per day $\left(\bar{n}_{c}\right)$ by children in suburban, estate, and central areas.
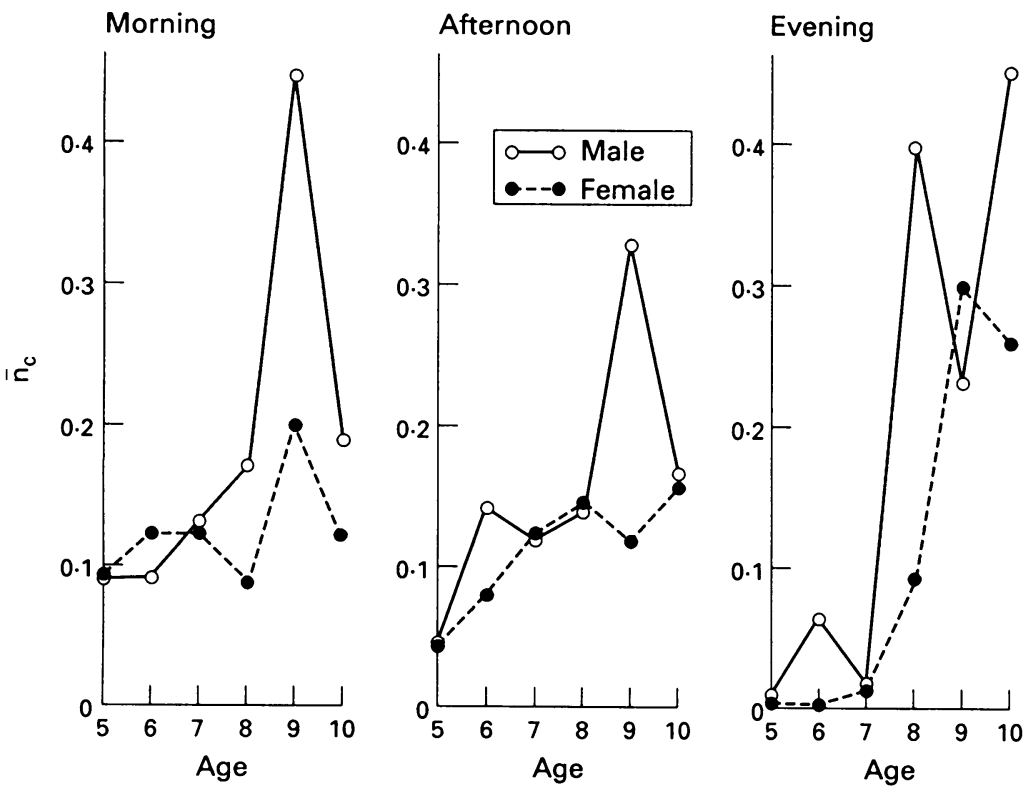

Figure 14 Average number of cars encountered $\left(\bar{n}_{c}\right)$ at different times of day.

Table 5 Values of $\bar{r}$ and $\bar{n}_{c}$ for children making different journeys during the day

\begin{tabular}{lllll}
\hline & $\begin{array}{l}\text { Lunchtime journey } \\
\text { and } \\
\text { evening journey }\end{array}$ & $\begin{array}{l}\text { Lunchtime journey } \\
\text { no } \\
\text { evening journey }\end{array}$ & $\begin{array}{l}\text { School lunch } \\
\text { and } \\
\text { evening journey }\end{array}$ & $\begin{array}{l}\text { School lunch } \\
\text { no } \\
\text { evening journey }\end{array}$ \\
\hline $\bar{r}$ & $13 \cdot 6$ & $8 \cdot 8$ & $10 \cdot 2$ & $3 \cdot 7$ \\
$\bar{n}_{c}$ & $0 \cdot 53$ & $0 \cdot 20$ & $0 \cdot 43$ & $0 \cdot 13$ \\
No of cases & 37 & 119 & 39 & 93 \\
\hline
\end{tabular}

the not unexpected one that the very young children are comparatively little exposed to traffic in the evening.

5. Recalculation of $\boldsymbol{P}_{a r}$ and $\boldsymbol{P}_{a / c}$ with Nottingham accident statistics

The calculations of $p_{a r}$ and $p_{a / c}$ presented above were based on projected national population figures from the 1961 census and the national fatal and serious accident statistics for each age and sex group. We have also calculated these values using the Nottingham City accident statistics and the population figures published in the advance analysis of the 1971 consensus for Nottinghamshire.
These estimates for each age and sex group are shown in figures 15 and 16. They are not directly comparable with figures 6 and 10 because $p_{a}$ is calculated from the Nottingham fatal, serious, and slight accidents whereas only the fatal and serious national accidents were used in the original calculations. Although there is some doubt as to the reliability of the recorded numbers of slight accidents it was necessary to include them in order to have sufficient Nottingham data.

The new figures are very similar in overall shape to the originals, showing the same general features, namely, a marked decline in both $p_{a r}$ and $p_{a / c}$ with age especially for the boys, and higher values of both for the boys than the girls in the younger age groups, with the differences disappearing by the age of eight.

The differences in the values of $p_{a r}$ and $p_{a / c}$ between the younger boys and girls are clearly significant in the original calculations. Natually, the new variance estimates of $p_{a}$, and consequently of $p_{a r}$ and $p_{a / c}$ are somewhat greater than those of the original calculations since $\mathrm{N}$, the number of children in the population, is approximately 150 times smaller for Nottingham than for the whole country. The standard errors of the mean for the new values indicate that the differences between the boys and the girls are not as reliable as before. However, $p_{a r}$ and $p_{a / c}$ were calculated from two and three different sources of data, respectively. The variance of $p_{a r}$ was calculated by combining the variances of $p_{a}$ and $r$, but since $p_{a}$ and $r$ are likely to be positively correlated, the value given will probably be an overestimate of the variance of $p_{a r}$. Similarly we have assumed that the variables used to calculate $p_{a / c}$ are

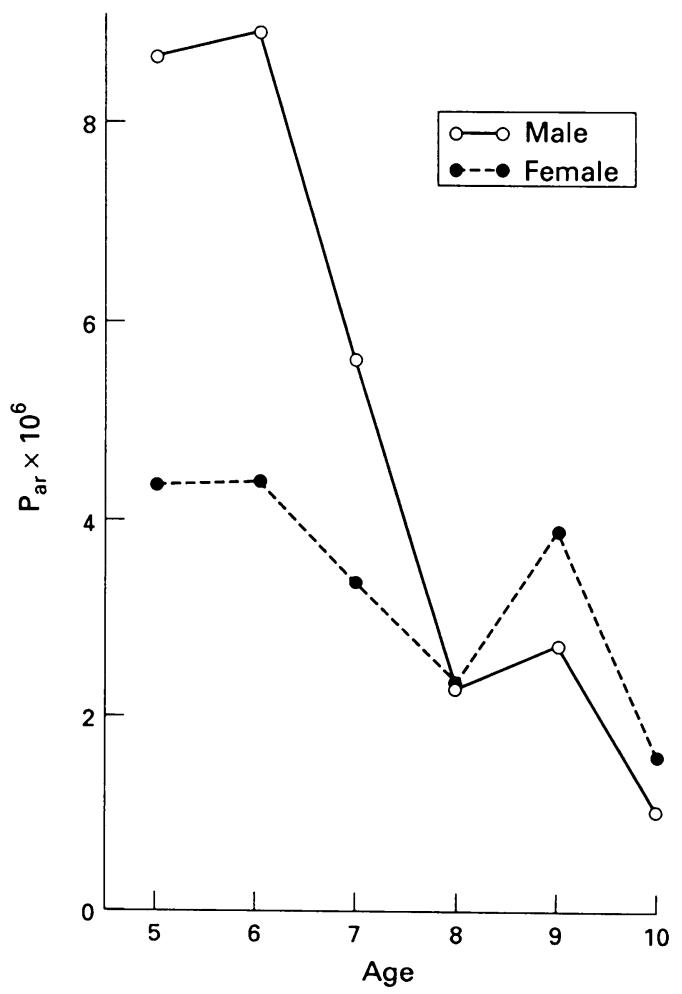

Figure 15 Risk per road crossing ( $p_{a r}$ ) on all roads, based on Nottingham accident statistics. 


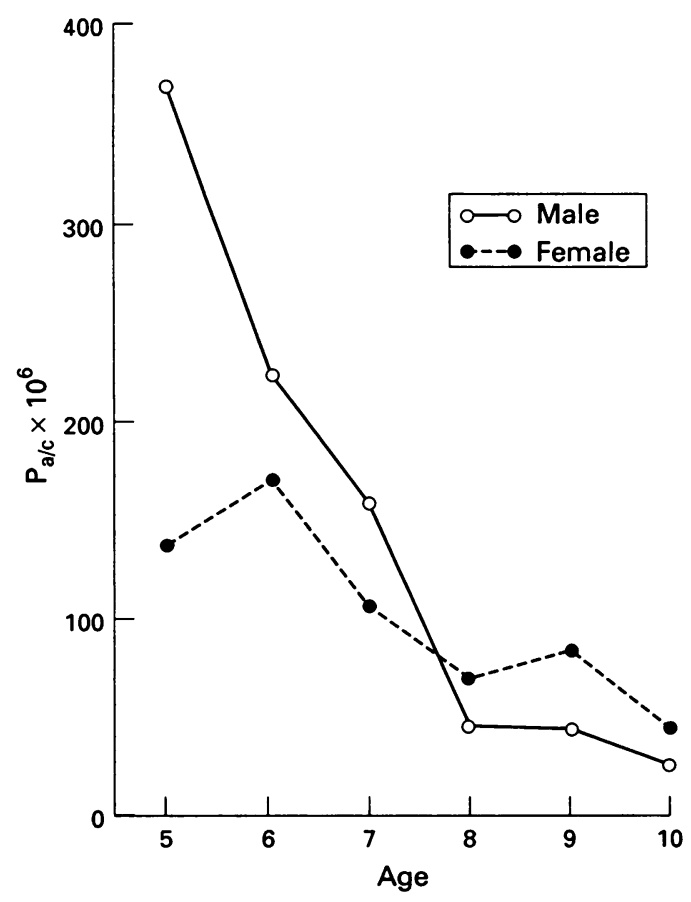

Figure 16 The risk per encounter with a car $\left(p_{a / c}\right)$ on all roads based on Nottingham accident statistics.

uncorrelated, but since any correlations between $p_{a}$ and either $r$ or $p_{c}$ are likely to be positive, and any correlations between $r$ and $p_{c}$ are likely to be negative, the calculation of the variance of $p_{a / c}$ by the method used is also likely to produce an overestimate.

One further feature of interest to arise from this recalculation is that the value of $p_{a}$ for fatal, serious, and slight accidents for Nottingham is considerably higher at each age and for both sexes than the national value. This is shown in table 6 .

The value $p_{a}$ is simply the number of accidents per day divided by the number of children in the population to which the accident statistic refers. It indicates that Nottingham children for some reason run a greater risk of being involved in an accident as a pedestrian, than the national average. We know from the national accident records that the number of accidents to children in rural areas is very considerably smaller than the number to children in urban areas and it seems reasonable to assume that the number to children living in rural areas is also considerably smaller than in urban areas. The comparison between $p_{a}$ for Nottingham City and the country as a whole suggests then that some areas with a high concentration of children have relatively fewer accidents than others. The reason for such

Table $6 p_{a} \times 10^{6}$ for fatal, serious, and slight accidents throughout the year

\begin{tabular}{|c|c|c|c|c|}
\hline \multirow[b]{2}{*}{ Age } & \multicolumn{2}{|l|}{ Male } & \multicolumn{2}{|l|}{ Female } \\
\hline & Nottingham & National & Nottingham & National \\
\hline $\begin{array}{r}5 \\
6 \\
7 \\
8 \\
9 \\
10\end{array}$ & $\begin{array}{l}35.9 \\
31.3 \\
28.5 \\
19.8 \\
20.3 \\
13.8\end{array}$ & $\begin{array}{l}19.2 \\
21.0 \\
19.8 \\
17.3 \\
13.8 \\
11.3\end{array}$ & $\begin{array}{r}19.5 \\
16.7 \\
18.8 \\
13.5 \\
13.5 \\
9.5\end{array}$ & $\begin{array}{r}10.1 \\
10.8 \\
10.2 \\
9.6 \\
9.0 \\
7.9\end{array}$ \\
\hline
\end{tabular}

differences may be simply a function of the number of roads the children cross. Alternative reasons may be that traffic is denser in some of the areas than in others or that, regardless of the density of traffic, road crossing in some areas may be more risky either for reasons of engineering, or lack of road safety training or propaganda.

Having identified areas with contrasting values of $p_{a}$ (a relatively simple and worthwhile exercise in itself), the next step should be to obtain values of $p_{a r}$ and $p_{a / c}$. This could be done relatively easily with exposure surveys similar to that carried out in Nottingham. Measures of $p_{a r}$ would establish the extent to which differences in $p_{a}$ between areas is simply a function of the number of roads crossed; in other words the risk involved in the particular children's current pattern of road crossing, while measures of $p_{a / c}$ would demonstrate the contribution of factors, if any, in addition to the number of roads crossed and the density of traffic on those roads. In other words, $p_{a / c}$ would provide a measure of the risk involved in children of a particular age and sex crossing roads of comparable traffic density in different areas.

The value of such information lies in the extent to which it enables decisions to be made about community planning, traffic engineering, propaganda, and training aimed at adults and children or the directions in which further research, for example on adult attitudes, should be directed.

\section{Parent survey}

As a check on the data provided by the children, the parents of 72 children in our sample were asked to provide similar information. This work was done under our supervision by two MA students. Their data were scored in the same way to give estimates of exposure. The parents were necessarily asked about different days, so that the correlation between the children's report and that of their parents will be reduced both by the accuracy with which both parents and children can report the children's behaviour and by the variability of the children's behaviour from day to day.

Correlations between the parent and child scores are quite high for the older age groups but low for the younger age groups, suggesting that rather than parents being unaware of the older children's activities, the younger children are not giving an accurate account of their activities. Closer inspection of the data indicates that the correlation is misleading. The absolute discrepancy between the parent and child accounts increases with the age of the children.

Figures $17 \mathrm{~A}, \mathrm{~B}$, and $\mathrm{C}$ show $\bar{n}_{c}$ calculated from the parents' accounts compared with $\bar{n}_{c}$ from the accounts of the children of these parents. The discrepancy increases with age and is most marked in the older boys. Comparison of individual questionnaires indicates the $41 / 72-\mathrm{ie}, 66 \%$ were in agreement to the equivalent of one minor road in the whole day's 

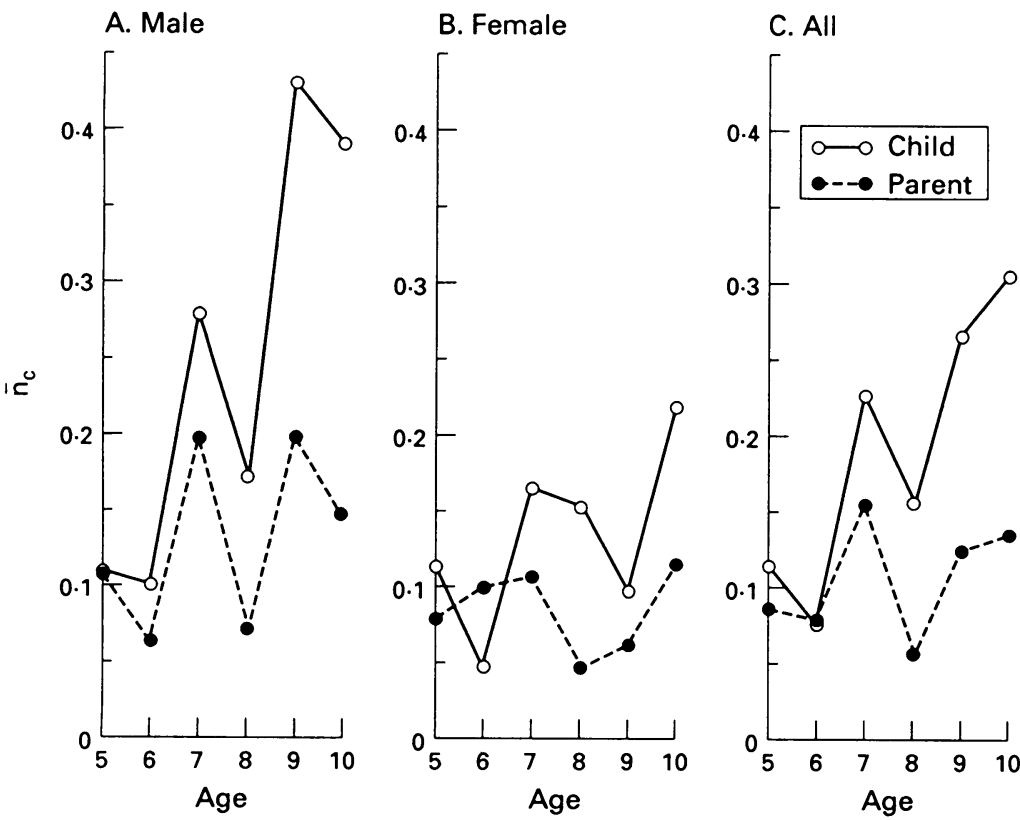

Figure 17 Estimated $\bar{n}_{c}$ from children's reports and from parent's reports.

journeys. The reasons for the differences in the remaining 31 cases are listed below.

\section{(1) ACCOMPANIMENT}

In 16 cases the child and mother disagreed as to who accompanies the child on one or more journeys. These included six cases where the mother simply said she usually accompanied the child, but according to the child did not on this particular day, seven cases where the mother said the child was accompanied by an elder child when the child said he was accompanied by a younger child or was alone. Often the child said he started out with an elder sibling but separated when he met his own friends. In three cases the mother thought the child was alone but the child claimed to have met friends who were accompanied by their mother.

\section{(2) DIFFERENT ROUTE}

In 13 instances the child said he took different route from that which the mother claimed. In all cases the mother's route was the more direct while the children claimed to have made detours either to call at friends' houses or to go to shops or a park to play.

\section{(3) MISCELLANEOUS}

In one case a child who was normally accompanied by her mother spent the night with friends and on the morning journey was unaccompanied by an adult. In another case the child made an unusually long journey at lunchtime to a relative's house because of an electricity strike. Two cases occurred of unresolved disagreement between the parent and child accounts. In one, the mother's manner and inconsistencies in her responses were such that the interviewer recorded at the time of the interview that she thought the mother was not telling the truth. In the other case the mother consistently claimed that the child was never exposed at all, to the extent of considering most of the general questions irrelevant. The child - a 7 year old - claimed, on the other hand, to have waited after school to walk home with friends who came out of school later than he and after going home subsequently went to his friends' house to play. We have no means of determining the truth in this instance.

There is, overall, considerably similarity in the results of the child and the parent surveys. The results of the parent survey are very much more variable than those from the child survey because of the very much smaller sample size. Nevertheless, the same general features are present, ie, an increase in exposure with age, but a bigger increase for boys than for girls. The exposures are similar in the younger age group but the boys were more exposed at the later ages according to their own accounts.

These results seem to us to justify the method of interviewing children rather than parents about children's exposure. We are not suggesting that the majority of parents deliberately give a false impression about the children's degree of protection, although there were a small number of instances in which the interviewers felt that this was the case. The analysis suggests that the majority of discrepancies between parents' and children's accounts arose because the children took a route other than the most obvious one or because they were not accompanied as the parents thought. It does appear, though, that asking what a child usually does or even asking parents about a specified day's journey is likely to underestimate exposure. A study which we have just completed, but which has not yet been fully analysed, provides very convincing evidence for this impression.

\section{Conclusion}

The results of both studies of children's exposure have been broadly similar. They show little evidence of a difference in the exposure of boys and girls, particularly in the younger children, where the difference in accident rates is so marked. They do show a pronounced and statistically highly significant increase in exposure with age for both sexes, whereas the accident rates, especially for the boys, are declining steeply over the age range studied. There are important results, since if validated, we could conclude that the reasons for the differences in the accident rates, between these groups are not to be found in the children's exposure to traffic, but must be looked for in their behaviour when crossing roads. However, we have already noted that we suspect that children under-report their exposure.

We are currently carrying out a study in which each child's account of the previous evening's journey is compared with observation of the child on the way home from school. This study will enable us to estimate the extent to which children under-report their exposure 
and to adjust our existing measures accordingly. It will also provide us with estimates of children's exposure at junctions and near stationary vehicles which can be related to the relevant accident statistics to provide measures of risk in these situations. In the same way that our initial estimates of risk enable comparison to be made of the behaviour of differentially risk groups of children, so such new estimates could be used to compare the behaviour of children in situations of differing risk.

This work was supported by a grant from the Department of the Environment's Transport and Road Research Laboratory, Crowthorne, Berkshire, England, as part of the research programme on road safety. National accident statistics were provided by their Accident Analysis Division.
Colbourne HV. Factors affecting the safety of young children as pedestrians. Unpublished MSc Thesis, University of Salford, 1972

Hole V. Children's play in housing estates. Ministry of Technology, Building Research Station, research paper 39. London: HM Stationery Office, 1966.

Holme A, Massie P. Children's play: a study of needs and opportunities. London: Michael Joseph, 1970.

Howarth CL, Routledge DA, Repetto-Wright R. An analysis of road accidents involving child pedestrians. Ergonomics 1974; 17: $319-30$.

Jacobs HH. Research problems in accident prevention. Social Problems 1961; Spring: 320-431.

Jacobs GD, Wilson DG. A study of pedestrian risk in crossing busy roads in four towns. Ministry of Transport, Road Research Laboratory report LR106. Crowthorne: Road Reseach Laboratory, 1967.

Lievin PJ, Bruce AJ. The location of primary schools. Building Research Station current papers No 39/68, April, 1968.

Mellinger GD, Manheimer DI. An exposure-coping model of accident liability among children. Fournal of Health and Social Behaviour 1967; 8: 96-106.

Newson J, Newson E. Four years old in an urban community. London: George Allen \& Unwin, 1968.

Newson J, Newson E. Personal communication, 1973.

Newson J, Newson E. The seven-year old in his home environment. London: George Allen and Unwin (in press).

Sadler J. Children and road safety: a survey amongst mothers. Report No SS 450. (London: HM Stationery Office, 1972.

\section{Hazard of latex balloons}

Readers were alerted previously to this hazard. A report in $\mathcal{F} A M A$ (13 December 1995) notes that balloons cause $29 \%$ of 449 deaths in children due to aspirating foreign bodies reported to the Consumer Product and Safety Commission (US) between 1972 and 1992.

\section{Carbon monoxide detector works}

A family in Owen Sound (Canada) survived a carbon monoxide level 400 times above the allowable amount from a leaking hot water tank, thanks to a carbon monoxide detector they had installed days previously. These devices are contentious: readers who know whether they really work or not are encouraged to share their knowledge with others through this journal. A similar episode is described in the winter issue of Campaign Update from the National SAFE KIDS Campaign (US).

\section{Res ipsa loquitor}

Local residents who have tried to convince the authorities to install a speed bump on a dangerous corner 'where drivers consistently ignore the stop signs' received the following reply from the police: 'Speed bumps cost $\$ 3000$ to install and remove'. A city councillor added that they 'were a pain, because they have to be removed every winter'. A spokesperson for the parents replied 'What's more of a pain - removing a speed bump, or dealing with an serious injury' (Gazette, 29 November 1995).

\section{Helmet law controversy: chapter $\mathrm{XXX}$}

Three municipalities in the Montreal area have now introduced helmet laws. The provincial minister still refuses because 'it would be difficult to enforce'. An interesting twist to the controversy is the fear that 'If you have a bylaw and don't enforce it and something happens, we've been told that legally (the victim) could sue us', explained a public safety inspector. (Editor's note: would that it were so!) And a typical response from a cycling refusenik: 'Helmets give cyclists false sense of safety and perhaps encourage daredevil-type behavior. I see people wearing helmets who do things I wouldn't do - darting in and out of traffic'. (Editor's note: worth studying?) 